\title{
Pre-Hospital Oxygen Therapy
}

\author{
Richard D Branson MSc RRT FAARC and Jay A Johannigman MD
}

\author{
Introduction \\ Cardiovascular Disease \\ Oxygen for Acute Myocardial Infarction \\ Stroke \\ Cardiac Arrest \\ Respiratory Disease \\ Chronic Obstructive Pulmonary Disease \\ Congestive Heart Failure and Pulmonary Edema \\ Other Pulmonary Diseases \\ Trauma \\ Traumatic Injury \\ Other Conditions \\ Pregnancy \\ Breathlessness \\ Sickle Cell Crisis \\ Carbon Monoxide Poisoning \\ Summary
}

\begin{abstract}
Oxygen use in prehospital care is aimed at treating or preventing hypoxemia. However, excess oxygen delivery has important consequences in select patients, and hyperoxia can adversely impact outcome. The unique environment of prehospital care poses logistical and educational challenges. Oxygen therapy in prehospital care should be provided to patients with hypoxemia and titrated to achieve normoxemia. Changes to the current practice of oxygen delivery in prehospital care are needed. [Respir Care 2013;58(1):86-94. (C) 2013 Daedalus Enterprises]
\end{abstract}

\section{Introduction}

Oxygen is a powerful drug that is commonly delivered in pre-hospital care without indication and in variable and unknown concentrations. Oxygen delivery can be monitored by pulse oximetry, typically with a goal of reversing hypoxemia. However, oxygen is rarely titrated in pre-hos-

The authors are affiliated with the Division of Trauma and Critical Care, Department of Surgery, University of Cincinnati, Cincinnati, Ohio.

Mr Branson has disclosed relationships with Advanced Circulatory Systems, Ikaria, and General Electric. This research was party supported by the Office of Naval Research and the United States Air Force 711th Human Performance Wing. pital care once hypoxemia has been reversed. Hyperoxia is a common finding upon hospital arrival in those patients who are administered oxygen in pre-hospital care. In fact, hyperoxia can be as common as hypoxia. ${ }^{1-4}$

The only evidence-based indication for oxygen therapy is hypoxemia confirmed by oximetry, blood gas analysis, or physical observation. However, oxygen is also often

\footnotetext{
Correspondence: Richard D Branson MSc RRT FAARC, Division of Trauma and Critical Care, Department of Surgery, University of Cincinnati, 231 Albert Sabin Way, Cincinnati OH 45267-0558. E-mail: richard. branson@uc.edu.
}

DOI: $10.4187 /$ respcare.02251 
delivered on presumption of need based on disease state (head injury, stroke, myocardial infarction, etc), to alleviate breathlessness, and to prevent hypoxemia in sick patients at risk. These presumptions are not based on evidence that oxygen is useful in these situations, but rather the belief that the oxygen will provide relief of symptoms or prevent untoward effects of hypoxemia. However, oxygen delivery to patents without hypoxemia can lead to worsening outcomes in the presence of hyperoxia. ${ }^{5-6}$

Data from a recent audit of British ambulance services demonstrate that $34 \%$ of all transports involve the delivery of oxygen. ${ }^{5}$ Data from the United Kingdom also suggest that, at any given time, $18 \%$ of hospitalized patients are receiving oxygen. ${ }^{6}$ In a small study ${ }^{7}(n=36)$ of oxygen delivery in a Victoria, Australia, emergency department, the most common reasons for oxygen administration were shortness of breath (40\%), chest pain (35\%), and hypoxemia (30\%). Patients receiving oxygen were older, more likely to have arrived by ambulance, and more likely to be admitted to the hospital. Nearly half of the patients in the study received oxygen. Collectively, these data suggest that oxygen is the most common drug delivered to patients following medical and surgical emergencies. Interestingly, while oxygen is perhaps the most commonly administered drug, it is not necessarily the most commonly prescribed.

This paper will review the current organizational guidelines for oxygen delivery in pre-hospital care and the current evidence from human trials demonstrating the safety, efficacy, and complications of pre-hospital oxygen therapy.

\section{Cardiovascular Disease}

\section{Oxygen for Acute Myocardial Infarction}

Oxygen therapy has been advocated for the treatment of acute myocardial infarction (AMI) and chest pain for nearly three quarters of a century. Barach was among the first to describe the salutary effects of oxygen therapy in patients with myocardial occlusion. ${ }^{8,9}$ In 1940, Boland described the prevailing notions of the time and noted:

There are 2 immediate objectives in the treatment of patients with acute coronary thrombosis, namely the support of the circulation and the relief of pain. The beneficial effects of oxygen administration in sustaining cardiorespiratory function, especially when significant degrees of shock or pulmonary edema exist, are well known. It is not widely recognized, however, that the inhalation of oxygen in high concentrations is effective in alleviating pain associated with coronary thrombosis and angina pectoris. ${ }^{10}$

Boland goes on to explain that, while the use of opiates typically alleviates pain from angina, in cases where opi- ates are insufficient, oxygen is an important "therapeutic adjunct." Boothby and colleagues, part of the team to develop the BLB (Boothby, Lovelace, Bulbulain) mask, made similar observations on the role of $100 \%$ oxygen for relief of chest pain. ${ }^{11}$

However, as early as 1950, Russek and co-workers began to question the rationale for the use of high oxygen concentrations in the treatment of angina in the absence of pulmonary edema and shock. ${ }^{12}$ These investigators studied 5 patients during the Master 2-step exercise test, which demonstrated electrocardiographic changes upon repeat testing. They administered nitroglycerine and high inspired oxygen concentrations prior to exercise. They noted:

In each of the 5 cases studied the administration of $100 \%$ oxygen was without effect in preventing the RS-T segment and $\mathrm{T}$ wave changes observed in the control records. Similarly, the continuous administration of $100 \%$ oxygen during the post-exercise period failed to hasten the disappearance of the electrocardiographic manifestations of myocardial anoxia. On the contrary, when $100 \%$ oxygen had been administered these changes were either more pronounced or longer in evidence in 4 of the 5 cases. In every instance, moreover, oxygen failed to prevent the onset of anginal pain or to influence its duration. In striking contrast, the administration of one tablet of nitroglycerin before the test not only prevented the subsequent development of anginal pain but greatly influenced the electrocardiographic response to standard exercise. ${ }^{12}$

Despite this exquisitely controlled experiment and convincing findings demonstrating no salutary effects of oxygen in alleviating chest pain, the routine use of oxygen therapy following suspected myocardial infarction continued for another 50 years.

In recent years, the role of oxygen therapy in AMI has been studied and new recommendations have been published. Early work by Ganz et al demonstrated the importance of oxygen tension on coronary artery blood flow. ${ }^{13}$ While the impact of hypoxia on coronary blood flow was anticipated, delivery of high concentrations of oxygen also resulted in reductions in coronary blood flow as a consequence of increased coronary vascular resistance. In these experiments, myocardial oxygen consumption was also reduced by approximately $16 \%$. Other investigators found similar effects in patients with and without congestive heart failure. ${ }^{14}$ McNulty and co-workers found significant reductions in coronary blood flow and myocardial oxygen consumption, accompanied by up to a $40 \%$ increase in coronary vascular resistance. ${ }^{15,16}$ It is important to note that these studies provided oxygen when oxygen tension was already normal. In the face of hypoxemia, oxygen administration may be warranted. However, these studies 
Table. Impact of Hyperoxemia on Coronary Artery Circulation and Myocardial Oxygen Demand in Normals and Patients With Cardiac Disease

\begin{tabular}{lccc}
\hline \hline First Author & $\begin{array}{c}\text { Change in Coronary } \\
\text { Blood Flow } \\
(\%)\end{array}$ & $\begin{array}{c}\text { Change in Coronary } \\
\text { Vascular Resistance } \\
(\%)\end{array}$ & $\begin{array}{c}\text { Change in Myocardial } \\
\text { Oxygen Consumption } \\
(\%)\end{array}$ \\
\hline Ganz $^{13}$ & -17.1 & 25 & -15.3 \\
Ganz $^{13}$ & -8.6 & 21.5 & -16.1 \\
Mak $^{14}$ & -7.9 & Not reported & Not reported \\
McNulty $^{15}$ & -28.9 & 40.9 & -26.9 \\
McNulty $^{16}$ & -19.8 & 22.2 & Not reported \\
\hline
\end{tabular}

clearly demonstrate the need for targeted oxygen therapy based on oxygen saturation. ${ }^{17}$ The Table demonstrates changes in coronary blood flow, coronary vascular resistance, and myocardial oxygen consumption associated with oxygen delivery to patients and normal subjects without baseline hypoxemia.

Rawles and Kenmure randomized 200 consecutive patients with suspected AMI to receive either air or oxygen via face mask during the first 24 hours of hospitalization. ${ }^{18}$ Forty-three patients without AMI were excluded, leaving 157 patients in the final analysis. They found no significant difference in mortality, incidence of arrhythmias, use of analgesics, or systolic time intervals between groups. However, $\mathrm{P}_{\mathrm{aO}}$ was greater in the oxygen group and the incidence of sinus tachycardia was also greater. These authors conclude that routine oxygen delivery in uncomplicated AMI is unwarranted.

These findings have lead Beasley and colleagues and Wijesinghe and colleagues to suggest that the routine use of oxygen in AMI may lead to increased infarct size and greater mortality. ${ }^{19,20}$ Stub and co-workers have proposed the AVOID study (Air vs Oxygen in Myocardial Infarction study) in Victoria and Melbourne, Australia, ambulance services. This trial will enroll nearly 500 patients with ST-elevation AMI in the absence of hypoxia to receive either oxygen or air. The main outcome will be myocardial infarct size. To date, no preliminary data are available. $^{21}$

Finally, a Cochrane review from 2010 reviewed the use of oxygen for AMI. Unfortunately, the authors could identify only 3 randomized controlled trials where one group of patients received oxygen while the other received air. These studies included 387 patients. There were 14 deaths, and death was 3 times as likely to occur in the patients receiving oxygen. These small numbers cannot determine if this finding is causative, but clearly supports the need for reassessment of oxygen delivery in patients with AMI and normoxia. ${ }^{22}$ For its part, the most recent American Heart Association Emergency Cardiac Care guidelines took these findings into account. The current recommendations suggest that emergency medical services (EMS) providers may deliver oxygen during the initial assessment of patients with acute coronary syndrome. The recommenda- tions note that there is no evidence for routine use of oxygen in uncomplicated acute coronary syndrome. In the presence of dyspnea, hypoxemia as judged by pulse oximetry, or signs of heart failure, oxygen should be titrated to an $\mathrm{S}_{\mathrm{pO}_{2}}$ of $\geq 94 \% .{ }^{23}$ This is considered class I evidence with a level of evidence of $\mathrm{C}$.

These scientific findings represent a conundrum for the EMS practitioner and EMS physician. The EMS provider holds the responsibility of determining dyspnea or "signs of heart failure" in a busy and hurried environment. In these instances it might prove more efficient to give all patients oxygen until arrival at the hospital. However, pulse oximetry can simplify this problem by identifying hypoxemia. Additionally, training of EMS practitioners to use low flow oxygen appliances versus the ubiquitous nonrebreathing mask may help alleviate hyperoxemia.

\section{Stroke}

Stroke has a number of similarities to AMI, in terms of both the presence of ischemia and reperfusion, so much so that stroke is considered a "brain attack." Guidelines for the treatment of stroke in the early 1990s encouraged the use of oxygen in stroke patients who have hypoxemia, but not for routine use. ${ }^{24,25}$ Following stroke, patients may suffer from aspiration and/or hypoventilation leading to hypoxemia. However, hyperoxia is associated with cerebral vasoconstriction with consequent reductions in cerebral blood flow and can increase the presence of oxygen free radicals potentiating ischemia/reperfusion injury. ${ }^{26-28}$

Rønning and Guldvog studied 550 patients randomized to receive either oxygen by nasal cannula for the first 24 hours following stroke, or to a control group with no additional oxygen. They followed patients for up to 7 months following discharge, and evaluated the severity of disability based on a stroke score. ${ }^{29}$ They found that patients with mild to moderate strokes and no evidence of hypoxemia had a trend toward increased mortality. Interestingly, patients with severe strokes and consequent hypoxemia had a nonsignificant improvement in outcome. The authors concluded that oxygen supplementation given as routine treatment does not appear to be of benefit for stroke victims. 
Pancioli and colleagues evaluated the use of oxygen in patients with stroke, using a retrospective chart review. ${ }^{30}$ They evaluated 167 patients and found that there were indications for oxygen therapy in less than half of the patients. These indications included an $\mathrm{S}_{\mathrm{pO}_{2}} \leq 92 \%$, breathing frequency $>24$ breaths/min, heart rate $>100$ beats/ min, dyspnea, cyanosis, the presence of dyshemoglobins, anemia (hemoglobin $<9 \mathrm{~g} / \mathrm{dL}$ ), and the presence of AMI or chronic lung disease. The most frequent indications for oxygen therapy were the presence of chronic lung disease, anemia, tachycardia, and tachypnea. This group noted that oxygen therapy is often given to stroke patients without indication and that reducing oxygen use might save resources and reduce costs. This study did not evaluate outcomes.

A more recent trial conducted in China suggests that controlled oxygen therapy using an air-entrainment mask, compared to a nasal cannula, was associated with fewer complications. However, this was a very small trial and included the first 24 hours of hospitalization. ${ }^{31}$ The most recent guidelines for treating stroke suggest that routine use of oxygen should be avoided and that the presence of hypoxemia is the best indication. ${ }^{32}$

\section{Cardiac Arrest}

During cardiopulmonary resuscitation, delivery of $100 \%$ oxygen during ventilation remains the current recommendation. ${ }^{33}$ However, the guidelines opine that there is a need to evaluate the role of a titrated oxygen mixture versus either the current standard or room air. This is in part the result of animal studies again suggesting that hyperoxia results in worse neurologic outcomes, as a consequence of ischemia/reperfusion injury. ${ }^{34-35}$

These findings have been further bolstered by a large clinical review of over 6,000 patients following cardiac arrest. Kilgannon and the Emergency Medicine Shock Research Network investigators found that, while hypoxia (63\%) was 3 times more likely to be present than both normoxia (19\%) and hyperoxia (18\%) following cardiac arrest, in-hospital mortality in the hyperoxia group was significantly greater. The odds ratio for death in the hyperoxia exposure group was 1.8 (95\% CI 1.5-2.2). ${ }^{36}$ These authors also evaluated mortality in ICU patients with hyperoxia and found that there was a dose dependent association between supranormal oxygen tension and risk of in-hospital death. They demonstrated that every $100 \mathrm{~mm} \mathrm{Hg}$ increase in post-resuscitation $\mathrm{P}_{\mathrm{aO}_{2}}$ was associated with a $24 \%$ increase in relative risk of death. However, they did not find a threshold under or over which hyperoxia was more or less severe. ${ }^{37}$

While these data are compelling, the risk of hypoxemia is not without import. Further research needs to evaluate the appropriate $\mathrm{F}_{\mathrm{IO}_{2}}$ delivery during cardiopulmonary re- suscitation, and, perhaps more importantly, what the target oxygen level will be and how to measure it.

\section{Respiratory Disease}

While the presence of hypoxemia in the face of unknown lung disease should be treated with oxygen without delay in the pre-hospital environment, there are specific areas where oxygen therapy should be more carefully addressed. Perhaps the most complete guidelines for the use of oxygen in emergency situations is published by the British Thoracic Society. ${ }^{38}$ The following discussion will refer strictly to use in pre-hospital care of common diseases.

\section{Chronic Obstructive Pulmonary Disease}

The dangers of high flow oxygen in the presence of COPD were described over 50 years ago by Campbell in a landmark paper in the Lancet. ${ }^{39} \mathrm{He}$ described 4 cases in patients with chronic bronchitis, emphysema, and bronchopneumonia. While the seminal observation was that high levels of inspired oxygen resulted in hypercapnia due to "respiratory depression," it may be that the observation was correct but the attribution was incomplete. Work in the 1980s by Milic-Emili and colleagues suggests that alterations in ventilation-perfusion matching resulting from loss of adaptive regulatory mechanisms were responsible for hypercarbia. ${ }^{40-42}$ Regardless, over half a century ago, Campbell suggested that patients with acute on chronic respiratory disease should receive oxygen, "continuously by a method which permits the inspired concentration to be controlled within limits of $\pm 1 \%$ over the range of 24-35\%."

More recently, a number of trials have evaluated the role of pre-hospital oxygen use in patients with COPD. Durrington et al evaluated pre-hospital oxygen delivery in Norfolk and Norwich in the United Kingdom, where transport times are commonly longer than $30 \mathrm{~min} .{ }^{43}$ They hypothesized that with prolonged transport times the impact of excess oxygen delivery might be exaggerated. They retrospectively reviewed patients admitted with exacerbations of COPD over 2 time frames. The first 108 patients were reviewed, and, after a period of training, a second group was reviewed. The intervention between the 2 time frames was introduction of an air-entrainment oxygen mask set at an $\mathrm{F}_{\mathrm{IO}_{2}}$ of 0.28 for initial management. Patients in the first group with $\mathrm{F}_{\mathrm{IO}_{2}}>0.28$ had a greater incidence of acidosis, hypercarbia, and hyperoxia (Fig. 1). These patients were also more likely to have a complicated hospital course, more likely to receive aminophylline, noninvasive ventilation, and invasive ventilation, and had a higher mortality rate. 


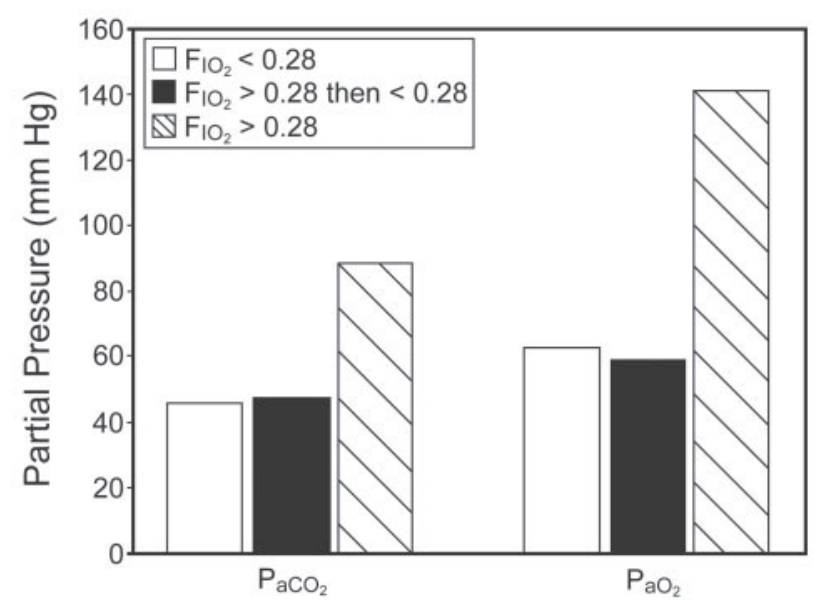

Fig. 1. Changes in $\mathrm{P}_{\mathrm{aCO}}$ and $\mathrm{P}_{\mathrm{aO}}$ during pre-hospital oxygen delivery at $\mathrm{F}_{\mathrm{IO}_{2}} \leq 0.28$, initial $\mathrm{F}_{\mathrm{IO}_{2}} \geq 0.28$ changed to $\leq 0.28$, and $\mathrm{F}_{\mathrm{IO}_{2}} \geq 0.28$. (Based on data from Reference 43.)

Cameron and others evaluated the outcome of patients with COPD exacerbation admitted to a New Zealand regional emergency department over 30 months. ${ }^{44}$ There were 680 patients presenting with COPD exacerbation, and 254 emergency admissions, representing 180 patients, were available for analysis. They found that hyperoxemia occurred in nearly a quarter of all admissions, and that, compared to normoxemia, the number of adverse outcomes were significantly greater (odds ratio 9.1, 95\% CI 4.0820.6). They also demonstrated that hypoxemia was associated with adverse outcomes (odds ratio $2.16,95 \%$ CI 1.11-4.20). Clinically speaking, the hyperoxia group presented with an $\mathrm{S}_{\mathrm{pO}_{2}}>96 \%$, and the hypoxemia group with an $\mathrm{S}_{\mathrm{pO}_{2}}$ of $<88 \%$. These data argue strongly for the use of titrated oxygen delivery in the patient with COPD.

Austin and colleagues compared high flow oxygen versus titrated oxygen treatment in a group of patients with COPD exacerbation in Tasmania. ${ }^{45}$ They evaluated 214 patients with a diagnosis of COPD exacerbation, of whom 117 received high flow oxygen and 97 received titrated oxygen therapy. In this group the mortality was 9\% (11/ $117)$ in the high flow oxygen group, and $2 \%(2 / 97)$ in the titrated oxygen group. Patients receiving titrated oxygen were far less likely to have acidosis or hypercapnia. Other authors have made similar findings in this group of patients. ${ }^{46}$

The British Thoracic Society has been a vocal advocate of changing practice to reduce excess oxygen exposure in these patients. ${ }^{6,47}$ The key to success is translation of this information into practice by EMS providers. This will include the addition of specialized equipment to provide high flow, low $\mathrm{F}_{\mathrm{IO}_{2}}$ to patients at risk. ${ }^{48}$ The British Thoracic Society suggests that all EMS units carry a nonrebreathing mask for high flow oxygen delivery, a nasal cannula or simple mask for low flow oxygen delivery,

\section{OXYGEN ALERT CARD}

Patient's Name

I am at risk of respiratory failure with a high $\mathrm{CO}_{2}$. Please use a $28 \%$ Venturi mask to maintain my $\mathrm{SpO}_{2}$ between $89 \%$ and $92 \%$ if I am ill. If I need nebulizer treatments, use room air to operate the nebulizer and deliver oxygen via nasal cannula at $2 \mathrm{~L} / \mathrm{min}$.

Fig. 2. Proposed example of an oxygen alert card that can be provided to patients with chronic respiratory disease at risk for hypercarbia. This includes patients with COPD as well as those with neuromuscular disease and obesity hypoventilation syndrome.

tracheostomy masks for patients with tracheostomy or laryngectomy, and a 28\% air entrainment mask. Another important issue is educating pre-hospital providers to operate up-draft nebulizers with room air if metered-dose inhalers are unavailable. During nebulizer treatments, oxygen can be provided at $2 \mathrm{~L} / \mathrm{min}$ via nasal cannula. Another interesting aspect is the concept of providing patients with cards identifying themselves as having COPD and requesting use of a low $\mathrm{F}_{\mathrm{IO}_{2}}$ air entrainment mask during ambulance transport. This has been suggested by the British Thoracic Society. A possible example is shown in Figure 2.

Oxygen therapy in patients with COPD is the classic story of Goldilocks and the Three Bears. Oxygen delivery cannot be too much or too little, but just right. The complexity of making the just right approach a reality requires substantial education, training, and cooperation from patients, hospitals, and EMS providers. ${ }^{49}$

\section{Congestive Heart Failure and Pulmonary Edema}

Congestive heart failure and pulmonary edema represent a common etiology behind the pre-hospital complaint of "shortness of breath." ${ }_{50}$ While hypoxemia is a clear symptom of pulmonary edema, administration of oxygen has limited value in a fluid-filled lung. The use of prehospital CPAP and noninvasive ventilation has increased to treat congestive heart failure and pulmonary edema. ${ }^{51-57}$ These studies have demonstrated reduced need for intubation, shorter hospital stays, and reduced costs with CPAP and or noninvasive ventilation, compared to oxygen with similar medical therapies.

With respect to the use of oxygen in congestive heart failure and pulmonary edema, the paper by Bledsoe et al addresses this directly. ${ }^{51}$ They evaluated 340 patients with respiratory distress in the pre-hospital setting. Nearly half of the patients presented with symptoms of congestive heart failure/acute pulmonary edema. These authors found that CPAP at an $\mathrm{F}_{\mathrm{IO}_{2}}$ of $0.28-0.3$ was effective in treat- 


\begin{tabular}{|c|c|c|c|c|}
\hline \multicolumn{2}{|c|}{$\begin{array}{l}\text { Airway Managment and Oxygen Delivery } \\
\text { Based on Patient Breathing Frequency }\end{array}$} & \multicolumn{3}{|c|}{ Oxygen Delivery and Ventilation Devices } \\
\hline \multirow{3}{*}{$\frac{\text { Breathing Frequency }}{\text { Slow }(<12 \text { breaths } / \text { min })}$} & \multirow{3}{*}{$\begin{array}{c}\begin{array}{c}\text { Management } \\
\text { Assisted ventilation }\end{array} \\
\mathrm{F}_{1 \mathrm{O}_{2} \geq 0.85}\end{array}$} & Device & Flow (L/min) & \multirow{3}{*}{$\begin{array}{c}\frac{\mathrm{F}_{1 \mathrm{O}_{2}}}{0.24-0.45} \\
0.50\end{array}$} \\
\hline & & $\overline{\text { Nasal cannula }}$ & $1-6$ & \\
\hline & & Mouth to mask & 10 & \\
\hline Normal (12-20 breaths/min) & \multirow{2}{*}{$\begin{array}{l}\text { Observe; consider } \\
\text { supplemental oxygen }\end{array}$} & Simple mask & $8-10$ & $0.40-0.60$ \\
\hline & & Bag valve mask & $8-10$ & $0.40-0.60$ \\
\hline \multirow{2}{*}{\multicolumn{2}{|c|}{ Too fast (20-30 breaths/min) Administer $\mathrm{F}_{1 \mathrm{O}_{2}} \geq 0.85$}} & Bag valve mask reservoir & ir $10-15$ & $0.90-1.0$ \\
\hline & & Non-rebreathing mask & $10-15$ & $0.90-1.0$ \\
\hline \multirow{2}{*}{$\begin{array}{l}\text { Abnormally fast } \\
\text { (>30 breaths/min) }\end{array}$} & \multirow{2}{*}{$\begin{array}{l}\text { Assisted ventilation } \\
\qquad \mathrm{F}_{1 \mathrm{O}_{2}} \geq 0.85\end{array}$} & Demand valve & NA & $0.90-1.0$ \\
\hline & & Ventilator & NA & $0.21-1.0$ \\
\hline
\end{tabular}

Fig. 3. Recommendations from the Pre-hospital Trauma Life Support (PHTLS) manual for $\mathrm{F}_{1 \mathrm{O}_{2}}$ delivery, based on breathing frequency and $\mathrm{F}_{\mathrm{IO}_{2}}$ capabilities of devices. The linking of this data results in a recommendation of an $\mathrm{F}_{\mathrm{IO}_{2}}$ of $>0.85$ in most cases. If the patient is spontaneously breathing this requires use of a non-rebreathing mask. NA $=$ not applicable.

ing patients with congestive heart failure and pulmonary edema. Only $6 \%$ of patients required pre-hospital intubation, and $70 \%$ of patients had improved upon arrival at the emergency department.

\section{Other Pulmonary Diseases}

The use of pre-hospital oxygen therapy in patients with pneumonia and asthma has been reported. ${ }^{58-60}$ Patients with pneumonia are likely to have a component of chronic lung disease, and, as such, high flow oxygen delivery can result in elevated $\mathrm{P}_{\mathrm{aCO}}{ }_{2}{ }^{58}$ Majumdar et al have shown that in patients with pneumonia a low $\mathrm{S}_{\mathrm{pO}_{2}}(<92 \%)$ is associated with greater mortality and morbidity at 30 days. This study evaluated 2,923 patients treated in Canadian emergency departments. ${ }^{59}$ They found that using a threshold for admission of an $\mathrm{S}_{\mathrm{pO}_{2}}<90 \%$ resulted in a number of subjects requiring readmission. These authors believe that raising the threshold for admission to $92 \%$ would be safer. This may provide a threshold for titrated oxygen therapy in pre-hospital care.

In patients with asthma, data suggest that oxygen should be provided only in the face of hypoxemia. Additionally, the work by Perrin et al ${ }^{60}$ suggests that high inspired oxygen leads to hypercapnia in a fashion similar to that seen during treatment of COPD.

\section{Trauma}

Traumatic illness and injury represent a wide variety of pathologies, commonly classified globally as blunt or penetrating. The spectrum of traumatic injury includes orthopedic fractures, pulmonary contusion, pneumothorax, airway obstruction, blood loss, traumatic brain injury, and solid organ injuries. While each can contribute to hypoxemia in a number of ways, the typical trauma patient in pre-hospital care is approached in a similar fashion based on the guidelines of Pre-hospital Trauma Life Support. ${ }^{61}$

\section{Traumatic Injury}

The requirement for oxygen in the treatment of trauma patients is not well described. Data from the Pre-hospital Trauma Life Support (PHTLS) manual suggest that oxygen delivery should be provided based on the patient's breathing frequency (Fig. 3). This methodology, along with the recommendations for oxygen delivery devices, results in the common default to a non-rebreathing mask at $15 \mathrm{~L} /$ min. The tables in Figure 3, are from different chapters in the Pre-hospital Trauma Life Support (PHTLS) manual. Together, however, they tend to encourage the use of high $\mathrm{F}_{\mathrm{IO}_{2}}$ in both spontaneously breathing patients and those requiring ventilatory support. With short transport times and multiple tasks required of the EMS provider, the use of the non-rebreathing mask simplifies care and reduces the number of required oxygen delivery devices in stock. Anecdotally, we have seen trauma patients with gunshot wounds to extremities arrive in the emergency department talking on their cell telephone held under the non-rebreather. The presumption is that high $\mathrm{F}_{\mathrm{IO}_{2}}$ is not toxic in these short time frames and that hypoxemia is far more dangerous.

The United States Special Operations Command provides some guidance on the use of oxygen for traumatic injury on the battlefield. ${ }^{62}$ These guidelines suggest that oxygen should be provided when oximetry identifies hypoxemia $\left(\mathrm{S}_{\mathrm{pO}_{2}}<92 \%\right)$. When oximetry is unavailable, oxygen is considered in casualties with loss of consciousness, traumatic brain injury, hemorrhagic shock, or casualty at altitude.

These recommendations carry conventional wisdom. Following traumatic brain injury, a single incidence of hypoxemia results in a worse neurologic outcome. This effect is associative; it is not clear if it is cause and effect. ${ }^{63-65}$ The use of oxygen in hemorrhagic shock is based on providing adequate oxygen delivery following massive blood loss. Kirkman and colleagues ${ }^{66}$ have shown that, following blast injury in a porcine model of controlled/ 
uncontrolled hemorrhage, maintenance of $\mathrm{S}_{\mathrm{pO}_{2}}$ at $95 \%$ is associated with prolonged survival times, compared to animals breathing room air. They also noted that animals breathing air had progressive decreases in base deficit, corresponding to inadequate oxygen delivery. Two thirds of the animals supplied oxygen survived, compared to no survivors in the room air group. Unfortunately, these authors did not define the amount of oxygen required to reverse hypoxemia. As oxygen is a precious, finite resource on the battlefield, knowing how much oxygen to deploy is critical.

Stockinger and McSwain evaluated oxygen use in prehospital trauma patients in New Orleans over a 33 month time frame. During this time, 5,090 trauma patients were brought to the trauma center. Of these, $57 \%$ of patients did not receive pre-hospital oxygen, while $43 \%$ did. Patients who received oxygen in the pre-hospital setting had a significantly greater mortality rate $(2.3 \%$ vs $1.1 \%)$. There was no difference in the outcomes among patients with blunt or penetrating injury. These data are intriguing. The authors concluded that oxygen does not improve outcome in trauma patients. It, however, might simply demonstrate that sicker patients receive oxygen in the pre-hospital environment. The number of subjects and range of injury severity is large, resulting in a very low mortality rate. ${ }^{67}$

How much oxygen trauma patients require is yet to be defined. Clearly, $15 \mathrm{~L} / \mathrm{min}$ by non-rebreathing mask is often excessive. We have shown that in mechanically ventilated casualties an average oxygen flow of $3 \mathrm{~L} / \mathrm{min}$ would suffice in a majority of patients. ${ }^{68}$ We have also presented preliminary data on the incidence of hypoxemia in patients following trauma and the utilization of oxygen in suspected traumatic brain injury. ${ }^{69,70}$ These data suggest that hypoxemia is not uncommon in pre-hospital transport of trauma patients (approximately 30\%). However, a number of pre-hospital causes of hypoxemia (airway obstruction, pneumo/hemothorax) are not amenable to oxygen treatment. Further work to determine the flow of oxygen to reverse hypoxemia is warranted.

Data suggest that oxygen should be given only to patients who demonstrate hypoxemia and that oxygen should be titrated to a normal $\mathrm{S}_{\mathrm{pO}_{2}}$. As in other conditions, hyperoxemia may have untoward effects in trauma patients, with and without traumatic brain injury. ${ }^{71}$

\section{Other Conditions}

A number of other pre-hospital conditions warrant the use of oxygen therapy in pre-hospital care or have been singled out for oxygen use. A small list is provided below.

\section{Pregnancy}

While pregnancy causes a restrictive pulmonary defect, and pregnant patients may present with a variety of critical illnesses in pre-hospital care, there is no evidence that pregnancy requires oxygen therapy more than any other health condition. ${ }^{72-74}$ Oxygen therapy in pregnancy should be titrated to underlying pathophysiology and guided by oximetry or blood gas analysis.

\section{Breathlessness}

Breathlessness is seen in patients with hypoxemia, but also in patients at the end of life, those with anxiety, and other illness not associated with hypoxemia. There is no evidence that oxygen delivery alleviates breathlessness in non-hypoxemic patients. ${ }^{75}$

\section{Sickle Cell Crisis}

Oxygen is often prescribed for the treatment of sickle cell disease, particularly in crisis. However there is a dearth of evidence supporting the effectiveness of oxygen in all patients. Oxygen therapy has not been shown to affect the duration of a pain crisis or to be useful in patients with acute chest syndrome with normoxemia. Oxygen should be administered only if hypoxemia is present. ${ }^{76-78}$

\section{Carbon Monoxide Poisoning}

The delivery of high concentrations of oxygen to patients with carbon monoxide poisoning is one condition where hyperoxemia is desirable. The half-life of carboxyhemoglobin is $4-5$ hours breathing room air. Breathing $100 \%$ oxygen reduces this to $40 \mathrm{~min} .79,80$

\section{Summary}

Oxygen is life-saving in the face of hypoxemia. The relatively common belief that oxygen is non-toxic over short exposures, logistical challenges, and training issues in pre-hospital care have resulted in routine excess oxygen use: excess not only in dose but in indications for conditions. At present, oxygen should be titrated to alleviate hypoxemia and prevent hyperoxemia, with treatment of carbon monoxide poisoning being the exception.

\section{REFERENCES}

1. Hopple J. No clue about $\mathrm{O}_{2}$ : teaching oxygen therapy to prehospital providers. JEMS 2011;36(12):26, 28-29.

2. Cornet AD, Kooter AJ, Peters MJ, Smulders YM. Supplemental oxygen therapy in medical emergencies: more harm than benefit? Arch Intern Med 2012;172(3):289-290.

3. Metcalfe M. Improving the safety of oxygen therapy in the treatment of acute myocardial infarctions. Int Emerg Nurs 2012;20(2):94-97.

4. Anderson D. Behind the mask: is oxygen harming your patient? JEMS 2011;36(7):50-55.

5. Hale KE, Gavin C, O'Driscoll BR. Audit of oxygen use in emergency ambulances and in a hospital emergency department. Emerg Med J 2008;25(11):773-776. 


\section{Pre-Hospital OXYgen Therapy}

6. O'Driscoll BR, Howard LS, Bucknall C, Welham SA, Davison AG; on behalf of the British Thoracic Society. British Thoracic Society emergency oxygen audits. Thorax 2011;66(8):734-735.

7. Considine J, Botti M, Shane T. Descriptive analysis of oxygen use in in an Australian emergency department. Eur J Emerg Med 2012; 19(1):48-52.

8. Barach AL. Therapeutic use of oxygen in heart disease. Ann Intern Med 1931;5(10):428.

9. Barach AL, Levy RL. Oxygen in treatment of acute coronary occlusion. JAMA 1934;103(12):1690-1693.

10. Boland EW. Oxygen in high concentrations for relief of pain in coronary thrombosis and severe angina pectoris. JAMA 1940;114(16): $1512-1514$

11. Boothby WM, Mayo CW, Lovelace WR Jr. One hundred percent oxygen: indications for its use and methods of its administration. JAMA 1939;113(6):477-482.

12. Russek HI, Regan FD, Naegele CF. One hundred percent oxygen in the treatment of acute myocardial infarction and severe angina pectoris. JAMA 1950;30:144(5):373-375.

13. Ganz W, Donoso R, Marcus H, Swan HJ. Coronary hemodynamics and myocardial oxygen metabolism during oxygen breathing in patients with and without coronary artery disease. Circulation 1972; 45(4):763-768.

14. Mak S, Azevedo ER, Liu PP, Newton GE. Effect of hyperoxia on left ventricular function and filling pressures in patients with and without congestive heart failure. Chest 2001;120(2):467-473.

15. McNulty PH, King N, Scott S, Hartman G, McCann J, Kozak M, et al. Effects of supplemental oxygen administration on coronary blood flow in patients undergoing cardiac catheterization. Am J Physiol Heart Circ Physiol 2005;288(3):H1057-H1062.

16. McNulty PH, Robertson BJ, Tulli MA, Hess J, Harach LA, Scott S, Sinoway LI. Effect of hyperoxia and vitamin $\mathrm{C}$ on coronary blood flow in patients with ischemic heart disease. J Appl Physiol 2007; 102(5):2040-2045.

17. Farquhar H, Weatherall M, Wijesinghe M, Perrin K, Ranchord A, Simmonds M, Beasley R. Systematic review of studies of the effect of hyperoxia on coronary blood flow. Am Heart J 2009;158(9):371377.

18. Rawles JM, Kenmure AC. Controlled trial of oxygen in uncomplicated myocardial infarction. BMJ 1976;1(6018):1121-1123.

19. Beasley R, Aldington S, Weatherall M, Robinson G, McHaffle D. Oxygen therapy in myocardial infarction: an historical perspective. J R Soc Med 2007;100(3):130-133.

20. Wijesinghe M, Perrin K, Ranchord A, Simmonds M, Weatherall M, Beasley R. Routine use of oxygen in the treatment of myocardial infarction: systematic review. Heart 2009;95(3):198-202.

21. Stub D, Smith K, Bernard S, Bray JE, Stephenson M, Cameron P, Meredith I, Kaye DM. A randomized controlled trial of oxygen therapy in acute myocardial infarction Air Verses Oxygen In myocarDial infarction study (AVOID Study). Am Heart J 2012;163(3): 339-345.

22. Cabello JB, Buris A, Emparanza JL, Bayliss S, Quinn T. Oxygen therapy for acute myocardial infarction. Cochrane Database Syst Rev 2010;16(6):CD007160

23. O'Connor RE, Brady W, Brooks SC, Diercks D, Egan J, Ghaemmaghami C, et al. Part 10: Acute coronary syndromes. 2010 American Heart Association guidelines for cardiopulmonary resuscitation and emergency cardiovascular care. Circulation 2010;2:122(18 Suppl 3):S787-S817. Erratum in: Circulation 2011;123(6):e238.

24. Norwegian Research Council. Treatment of Stroke Patients. Consensus Report No. 8. Oslo, Norway: Norwegian Research Council; 1995.

25. Adams HP Jr, Brott TG, Furlan AJ, Gomez CR, Grotta J, Helgason $\mathrm{CM}$, et al. Guidelines for thrombolytic therapy for acute stroke: a supplement to the guidelines for the management of patients with acute ischemic stroke. A statement for healthcare professionals from a Special Writing Group of the Stroke Council, American Heart Association. Stroke 1996;27(9):1711-1718.

26. Kety SS, Schmidt CF. The effects of altered tensions of carbon dioxide and oxygen on cerebral blood flow and cerebral oxygen consumption of normal young men. J Clin Invest 1948;27(4):484-492.

27. Hallenbeck J, Dutka A. Background review and current concepts of reperfusion injury. Arch Neurol 1990;47(11):1245-1254.

28. McCord JM. Oxygen-derived free radicals in postischemic tissue injury. N Engl J Med 1985;312(3):159-163.

29. Rønning OM, Guldvog B. Should stroke victims routinely receive supplemental oxygen? A quasi-randomized controlled trial. Stroke 1999;30(10):2033-2037.

30. Pancioli AM, Bullard MJ, Gruleee ME, Jauch EC, Perkis DF. Supplemental oxygen use in ischemic stroke patients: does utilization correspond to the need for oxygen? Arch Intern Med 2002;162(1):49-52.

31. Chiu EH, Liu CS, Tan TY, Chang KC. Venturi mask adjuvant oxygen therapy in severe acute ischemic stroke. Arch Neurol 2006; 63(5):741-744.

32. Jauch EC, Cucchiara B, Adeoye O, Meurer W, Brice J, Chan YY, et al. Part 11: adult stroke: 2010 American Heart Association Guidelines for cardiopulmonary resuscitation and emergency cardiovascular care. Circulation 2010;122(18 Suppl 3):S818-S828. Erratum in: Circulation 2011;124(15):e404.

33. Morrison LJ, Deakin CD, Morley PT, Callaway CW, Kerber RE, Kronick SL, et al. Part 8: Advanced life support: 2010 international consensus on cardiopulmonary resuscitation and emergency cardiovascular care science with treatment recommendations. Circulation 2010;122(16 Suppl 2):S345-S421.

34. Liu Y, Rosenthal RE, Haywood Y, Miljkovic-Lolic M, Vanderhoek JY, Fiskum G. Normoxic ventilation after cardiac arrest reduces oxidation of brain lipids and improves neurological outcome. Stroke 1998;29(8):1679-1686.

35. Zwemer CF, Whitesall SE, D'Alecy LG. Cardiopulmonary-cerebral resuscitation with $100 \%$ oxygen exacerbates neurological dysfunction following nine minutes of normothermic cardiac arrest in dogs. Resuscitation 1994;27(2):159-170.

36. Kilgannon JH, Jones AE, Shapiro NI, Angelos MG, Milcarek B, Hunter K, et al; Emergency Medicine Shock Research Network (EMShockNet). Association between arterial hyperoxia following resuscitation from cardiac arrest and in-hospital mortality. JAMA 2010; 303(21):2165-2171.

37. Kilgannon JH, Jones AE, Parrillo JE, Dellinger RP, Milcarek B, Hunter K, et al; Emergency Medicine Shock Research Network (EMShockNet). Relationship between supranormal oxygen tension and outcome after resuscitation from cardiac arrest. Circulation 2011; 123(23):2717-2722.

38. O'Driscoll BR, Howard LS, Davsion AG. British Thoracic Society guideline for emergency oxygen use in adult patients. Thorax 2008; 63(Suppl VI)1-68.

39. Campbell EJM. A method of controlled oxygen administration which reduces the risk of carbon dioxide retention. Lancet 1960;ii: 12-14.

40. Milic-Emili J, Aubier M. Some recent advances in the study of the control of breathing in patients with chronic obstructive lung disease. Anesth Analg 1980;59(11):865-873.

41. Aubier M, Murciano D, Fournier M, Milic-Emili J, Pariente R, Derenne JP. Central respiratory drive in acute respiratory failure of patients with chronic obstructive pulmonary disease. Am Rev Respir Dis 1980 Aug;122(2):191-199.

42. Aubier M, Murciano D, Milic-Emili J, Touaty E, Daghfous J, Pariente R, Derenne JP. Effects of the administration of $\mathrm{O}_{2}$ on ventilation and blood gases in patients with chronic obstructive pulmonary disease during acute respiratory failure. Am Rev Respir Dis 1980; 122(5):747-54. 


\section{Pre-Hospital OXYgen Therapy}

43. Durrington HJ, Flubacher M, Ramsay CF, Howard LS, Harrison BD. Initial oxygen management in patients with an exacerbation of chronic obstructive pulmonary disease. QJM 2005;98(7):499-504.

44. Cameron L, Pilcher J, Weatherall M, Beasley R, Perrin K. The risk of serious adverse outcomes associated with hypoxaemia and hyperoxaemia in acute exacerbations of COPD. Postgrad Med J 2012; 88(1046):684-689.

45. Austin MA, Wills KE, Blizzard L, Walters EH, Wood-Baker R. Effect of high flow oxygen on mortality in chronic obstructive pulmonary disease patients in prehospital setting: randomised controlled trial. BMJ 2010;341:c5462. DOI: 10.1136/bmj.c5462.

46. Wijesinghe M, Perrin K, Healy B, Hart K, Clay J, Weatherall M, Beasley R. Pre-hospital oxygen therapy in acute exacerbations of chronic obstructive pulmonary disease. Intern Med J 2011;41(8): 618-622.

47. O'Driscoll BR, Howard LS, Davison AG; British Thoracic Society. Emergency oxygen use in adult patients: concise guidance. Clin Med 2011;11(4):372-375.

48. O'Driscoll BR. Safe use of emergency oxygen in chronic respiratory disease. Chron Respir Dis 2011;8(3):159-161.

49. Burring L, Smith JE. Use of emergency oxygen in adult patients: implementing change. Emerg Med J 2011;28(3):249-250.

50. Kosowsky JM, Stephanides SL, Branson RD, Sayre MR. Prehospital use of continuous positive airway pressure (CPAP) for presumed pulmonary edema: a preliminary case series. Prehosp Emerg Care 2001;5(2):190-196.

51. Bledsoe BE, Anderson E, Hodnick R, Johnson L, Johnson S, Dievendorf E. Low-fractional oxygen concentration continuous positive airway pressure is effective in the prehospital setting. Prehosp Emerg Care 2012;16(2):217-221.

52. Kallio T, Kuisma M, Alaspää A, Rosenberg PH. The use of prehospital continuous positive airway pressure treatment in presumed acute severe pulmonary edema. Prehosp Emerg Care 2003;7(2):209-213.

53. Taylor DM, Bernard SA, Masci K, MacBean CE, Kennedy MP, Zalstein S. Prehospital noninvasive ventilation: a viable treatment option in the urban setting. Prehosp Emerg Care 2008;12(1):42-45.

54. Dib JE, Matin SA, Luckert A. Prehospital use of continuous positive airway pressure for acute severe congestive heart failure. J Emerg Med 2012;42(5):553-558.

55. Thompson J, Petrie DA, Ackroyd-Stolarz S, Bardua DJ. Out-ofhospital continuous positive airway pressure ventilation versus usual care in acute respiratory failure: a randomized controlled trial. Ann Emerg Med 2008;52(3):232-241.

56. Hubble MW, Richards ME, Jarvis R, Millikan T, Young D. Effectiveness of prehospital continuous positive airway pressure in the management of acute pulmonary edema. Prehosp Emerg Care 2006; 10(4):430-439.

57. Hubble MW, Richards ME, Wilfong DA. Estimates of cost-effectiveness of prehospital continuous positive airway pressure in the management of acute pulmonary edema. Prehosp Emerg Care 2008; 12(3):277-285.

58. Wijesinghe M, Perrin K, Healy B, Weatherall M, Beasley R. Randomized controlled trial of high concentration oxygen in suspected community-acquired pneumonia. J R Soc Med 2012;105(5):208-216.

59. Majumdar SR, Eurich DT, Gamble JM, Senthilselvan A, Marrie TJ. Oxygen saturations less than $92 \%$ are associated with major adverse events in outpatients with pneumonia: a population-based cohort study. Clin Infect Dis 20111;52(3):325-331.

60. Perrin K, Wijesinghe M, Healy B, Wadsworth K, Bowditch R, Bibby $\mathrm{S}$, et al. Randomised controlled trial of high concentration versus titrated oxygen therapy in severe exacerbations of asthma. Thorax 2011;66(11):937-941.

61. Salomone JP, Pons PT (editors). Prehospital trauma life support, 6th edition. St. Louis: Mosby/Elsevier; 2007.
62. Journal of Special Operations Medicine. 2012 training supplement. Tactical trauma protocols. Breakaway Media; 2012.

63. Franschman G, Peerdeman SM, Andriessen TM, Greuters S, Toor AE, Vos PE, et al; Amsterdam Lifeliner: Analysis of Results and Methods: Traumatic Brain Injury (ALARM-TBI) investigators. Effect of secondary prehospital risk factors on outcome in severe traumatic brain injury in the context of fast access to trauma care. J Trauma 2011;71(4):826-832.

64. Brain Trauma Foundation; American Association of Neurological Surgeons; Congress of Neurological Surgeons; Joint Section on Neurotrauma and CriticalCare, AANS/CNS; Bratton SL, Chestnut RM, Ghajar J, McConnell Hammond FF, Harris OA, Harti R, et al. Guidelines for the management of severe traumatic brain injury. I. Blood pressure and oxygenation. J Neurotrauma 2007;24(Suppl 1):S7-S13. Erratum in: J Neurotrauma 2008;25(3):276-278.

65. Chi JH, Knudson MM, Vassar MJ, McCarthy MC, Shapiro MB, Mallet $\mathrm{S}$, et al. Prehospital hypoxia affects outcome in patients with traumatic brain injury: a prospective multicenter study. J Trauma 2006;61(5):1134-1141

66. Kirkman E, Watts S, Cooper G. Blast injury research models. Philos Trans R Soc Lond B Biol Sci 2011;366(1562):144-159.

67. Stockinger ZT, McSwain NE Jr. Prehospital supplemental oxygen in trauma patients: its efficacy and implications for military medical care. Mil Med 2004;169(8):609-612.

68. Barnes SA, Branson RD, Beck G, Johannigman JA. En-route care in the air: a snapshot of mechanical ventilation at 37,000 feet. J Trauma 2008;64(Suppl):S129-S135.

69. McMullan J, Rodriquez D Jr, Hart K, Lindsell CJ, Branson R. Prevalence of hypoxemia and oxygen use in trauma patients prior to hospital arrival (abstract). Ann Emerg Med 2011;58(4):S242.

70. McMullan J, Hart K, Lindsell CJ, Branson R. Pre-hospital oxygen use in patients with decreased Glasgow Coma Scale, paramedic suspicion of traumatic brain injury, or confirmed head/neck injury (abstract). Neurocrit Care 2011;15(Suppl):S250.

71. Davis DP, Meade W, Sise MJ, Kennedy F, Simon F, Tominaga G, et al. Both hypoxemia and extreme hyperoxemia may be detrimental in patients with severe traumatic brain injury. J Neurotrauma 2009; 26(12):2217-2223.

72. Mateos Rodriguez AA, Benito Vellisca MA. Management of eclampsia in the prehospital setting. Emerg Med J 2007;24(7):504.

73. Colwell C, Murphy P, Bryan T. Prehospital management of the pregnant patient. Emerg Med Serv 2004;33(3):59-67, 76.

74. Pons PT. Prehospital considerations in the pregnant patient. Emerg Med Clin N Am 1994;12(1):1-7.

75. Johnson MJ, Abernethy AP, Currow DC. The evidence base for oxygen for chronic refractory breathlessness: issues, gaps, and a future work plan. J Pain Symptom Manage 2012:S08853924(12)00327-2. DOI: 10.1016/j.jpainsymman.2012.03.017.

76. Rees DC, Olujohungbe AD, Parker NE, Stephens AD, Telfer P, Wright J; British Committee for Standards in Haematology General Haematology Task Force by the Sickle Cell Working Party. Guidelines for the management of the acute painful crisis in sickle cell disease. Br J Haematol 2003;120(5):744-752.

77. Zipursky A, Robieux IC, Brown EJ, Shaw D, O'Brodovich H, Kellner JD, et al. Oxygen therapy in sickle cell disease. Am J Pediatr Hematol Oncol 1992;14(2):222-228.

78. Schulman LL. Oxygen therapy in sickle-cell anemia [letter]. N Engl J Med 1984;311(20):1319-1320.

79. Prockop LD, Chichkova RI. Carbon monoxide intoxication: an updated review. J Neurol Sci 2007;262(1-2):122-130.

80. Weaver LK, Howe S, Hopkins R, Chan KJ. Carboxyhemoglobin half-life in carbon monoxide-poisoned patients treated with $100 \%$ oxygen at atmospheric pressure. Chest 2000;117(3):801-808. 


\section{Discussion}

Owens: Rich, can you comment on the placebo effect of supplemental $\mathrm{O}_{2}$ on reducing breathing frequency and dyspnea? There might also be an anxiolytic effect of the EMS folks telling people their saturation is $100 \%$, so they can calm down and breathe more easily. I wonder if we are using supplemental oxygen as an anti-anxiety medication for both providers and patients, and maybe it doesn't have a lot to do with the actual saturation number?

Branson: I don't know, and I'm not sure how you'd approach that from an ethical standpoint. Maybe we do put people with an $\mathrm{S}_{\mathrm{pO}_{2}}$ of $95 \%$ on a nasal cannula with $4 \mathrm{~L} / \mathrm{min}$ of air and tell them that everything is going to be alright, but I don't know that anybody has considered that.

Bob McCoy talked about these $\mathrm{O}_{2}$ conserving systems that are made to preserve $\mathrm{O}_{2}$ and money for the people who provide the $\mathrm{O}_{2}$. In EMS it's "more is better": $15 \mathrm{~L} / \mathrm{min}$ is the rule. Which reminds me, when we were doing the closed loop oxygen research, one of the reasons we were doing it was to preserve $\mathrm{O}_{2}$. On a medical flight $\mathrm{O}_{2}$ is a finite resource. If you run out, there's nowhere else to get it. We told the FDA that our number-one specific aim was conserving $\mathrm{O}_{2}$, and the FDA told us that conserving $\mathrm{O}_{2}$ never helped anybody-it's not a patient benefit, so we couldn't use it as the end point. I thought, well, it helps when you're the one who's about to run out of it, but that would not help my cause at all.

Kallet: In response to that, patients with chronic pulmonary disease have reported that their breathlessness could be relieved by having cold air blow against their face. This led to research that confirmed that facial and upper airway thermal receptors mediate the sensation of dyspnea under conditions of loaded breathing and hypercapnia. ${ }^{1-3}$ I know when I'm in a muggy hot room my breathing is very uncomfortable, so there probably is something therapeutic about having the cool air against your face, even if it doesn't increase your $\mathrm{S}_{\mathrm{pO}_{2}}$.

McCoy: Aren't most of the CPAP systems in the back of the rig run with $100 \%$ oxygen? And is there any concern with giving $100 \% \mathrm{O}_{2}$ with CPAP?

Branson: The original CPAP systems all delivered low $\mathrm{F}_{\mathrm{IO}_{2}}$ : the Downs flow generator and the Caradyne delivered 33\%, and it's the CPAP that makes the difference in patients with CHF [congestive heart failure] and pulmonary edema: you don't need high $\mathrm{F}_{\mathrm{IO}_{2}}$. And those high-flow CPAP systems will run through an $\mathrm{H}$ cylinder pretty quick, and one of the problems with that technology ${ }^{4}$ is that the patient is on CPAP all the way to the hospital, and then you get to the ambulance bay, and there's no way to run the flow generator on a D cylinder, so you have to take the patient off of CPAP and put them on a nonrebreathing mask. Well, now their lungs fill with fluid and they start to have hypoxemia and they come into the emergency department and the doctor says "Why didn't you intubate him?" so then they intubate him.

There are problems with those CPAP systems. There are some newer CPAP systems that run on $100 \% \mathrm{O}_{2}$, and that's another case of giving a higher $\mathrm{F}_{\mathrm{IO}_{2}}$ than is necessary. We need a portable, ambulance CPAP system that provides a moderate $\mathrm{F}_{\mathrm{IO}_{2}}$. It doesn't have to be $85 \%$ or even $60 \%$ : $40 \%$ will do. The key is portability, so we can keep the patient on it from the time we pick them up at their home to the time they arrive in the emergency department. With the growing rate of obesity and increasing rate of COPD, we have to be even more careful about the amount of $\mathrm{O}_{2}$ we're administering to these patients on the way to the hospital.
McCoy: I've always wondered why they don't use the traditional CPAP that you would use at home for OSA [obstructive sleep apnea]. Is there some power issue that you can't use traditional home CPAP?

Branson: Blower-based devices are a lot more expensive. Some of the disposables are an issue, and the disposables can be very expensive. At least in my experience, in EMS they tend to get capital equipment so they can buy new technology, but then there's no money for any new disposables. So, whatever they buy, they have to be careful that it's not disposableintensive, or it can't be used. But I agree: somebody could make a compact high-flow generator with a battery that allows it to work when you're transferring the patient away from the ambulance, and with low-flow $\mathrm{O}_{2}$ and an $\mathrm{F}_{\mathrm{IO}_{2}}$ of 0.3 or 0.4 that would probably be more than enough for the average patient with CHF.

Hess:* I'm intrigued by Bob Owens's questions, and I'm thinking about some of the presentations from this morning. So I'll direct this question to Bob McCoy and Joe Lewarski. If you have a patient who's on 2 or $3 \mathrm{~L} / \mathrm{min}$ of continuous-flow $\mathrm{O}_{2}$ and then you switch them to a pulse-dose delivery system where they don't have that flow going into their nose but they have the same $\mathrm{O}_{2}$ saturation, do they ever complain that they're not getting the oxygen, or that they feel worse, or have some perception that things aren't as good? I think that might get to the question Bob was asking.

Owens: Some studies show some maybe small relief in dyspnea, whether you use air or oxygen. ${ }^{5}$ Again, this is

\footnotetext{
* Dean R Hess PhD RRT FAARC, Editor in Chief, Respiratory CARE, and Department of Respiratory Care, Massachusetts General Hospital, Harvard School of Medicine, Boston, Massachusetts.
} 
the concept of some sort of reflex mechanism-whether it's through the cranial nerves or what - that blowing cool air at the face makes you feel better. And can we use that without the side effects of too much oxygen?

Hess: You're the pulse dose experts.

Lewarski: $\uparrow \quad$ I have not seen any complaints of dyspnea or shortness of breath with appropriately titrated patients transitioning from continuousflow to pulse-dose. I have heard complaints about the noise of the bolus or the feel of the burst of $\mathrm{O}_{2}$ in the nose. I believe most of the complaints associated with transitioning a patient from continuous-flow to pulse-dose may be related to change: moving from a system they know and are comfortable with to a new system. We typically don't hear such concerns when you start a patient on pulse-dose who was previously naïve to home oxygen therapy. In some cases, if transition to continuous-flow after starting on pulse-dose, you get the opposite complaint: they say the extra flow is too much. The responses, concerns, and complaints vary by patient. But most of my experience is in the home: not in acute applications such as EMS.

Criner: Two bodies of literature look at this. Schwartzstein's data ${ }^{1}$ indicated that flow of air over the face stimulates trigeminal afferent receptors: that's like a diving response and decreases central motor output and breathing frequency. Data ${ }^{6} \mathrm{I}$ generated with Bart Celli years ago showed that normoxic COPD patients who breathed $30 \%$ oxygen, compared to compressed air, had a decrease in breathing frequency and preferential use of the diaphragm, as opposed to accessory muscles, during equivalent workloads. And Rich Casaburi ${ }^{7}$ and Dennis O'Donnell ${ }^{8}$ found the same

$\dagger$ Joseph S Lewarski RRT FAARC, Invacare, Elyria, Ohio. thing. The mechanism is that breathing frequency decreases, so you decrease the amount of gas trapping, and then you can probably use your diaphragm more than your accessory muscles. I think some of it is biologic, that you decrease the work of breathing and your central motor output. Especially in patients who are obstructed and hyperinflated to begin with - the COPD patient-you probably redistribute the ventilatory workload so that you are more likely to use your diaphragm to perform ventilatory work.

Pierson: This is a different out-ofhospital setting, but one in which the use of $\mathrm{O}_{2}$ seems fairly frequent. Is it beneficial to use $\mathrm{O}_{2}$ between downs in football games?

Branson: I'm going to say no.

Kevin Ward: It depends on who you're playing.

Criner: I know how that started. It was a respiratory therapist in Philadelphia who could never get Eagles tickets but brought an $\mathrm{O}_{2}$ tank to the field and started a tradition of over 30 years of bringing oxygen tanks to the sidelines.

Pierson: It's not the greatest example for the public to see the NFL players on the bench getting their $\mathrm{O}_{2}$ between sequences every Sunday.

Kallet: Good luck trying to take it away from them!

Treggiari: You showed a slide that indicated worse outcomes in patients who were hyperoxemic than in those who were hypoxemic. What mechanisms could explain that finding?

\$ David J Pierson MD FAARC, Emeritus, Division of Pulmonary and Critical Care Medicine, Harborview Medical Center, University of Washington, Seattle, Washington.
Branson: In that paper there were suggestions anywhere from the effects on coronary blood flow to something biochemical that occurs with pro-inflammatory mediators. It may be secondary to worsening of ischemia-reperfusion injury by oxygen radicals. It was not explained and was totally unanticipated. It was not one of their original hypotheses that hyperoxia would make patients worse. Do you have an idea?

Kevin Ward: I think part of the issue is wrong monitoring. We may be looking at the wrong side of the tree. Instead of looking at arterial saturation, maybe we ought to pay more attention to venous saturation. I don't want to steal Dr MacIntyre's thunder, but even in a low-flow state your arterial saturation can be very high but your tissues are starved. While $\mathrm{O}_{2}$ can certainly have effects from a cell signaling standpoint, if you were able to look noninvasively at the $\mathrm{O}_{2}$ extraction ratio, this might provide more information as to whether tissues actually need and respond to more oxygen delivery. Some of your data showed very poor brain tissue oxygen partial pressure and venous oxygen saturation, which may be where more of the answer lies. What do you think?

Branson: I agree. We just finished a study $^{1}$ where we were taking normal subjects to altitude (15,000 feet) and determining the amount of oxygen to overcome hypoxemia using a concentrator and pulse-dose delivery. At 15,000 feet your $\mathrm{O}_{2}$ saturation falls to about $81 \%$. People forget about the physiology at altitude; at 15,000 feet you have hypoxemia, but you only breathe about 6 times a minute, with a tidal volume of around 1.5 liters. This really impacts the $\mathrm{F}_{\mathrm{IO}_{2}}$ with low-flow or pulse-dose $\mathrm{O}_{2} . \mathrm{S}_{\mathrm{pO}_{2}}$ fluctuates wildly, but tissue $\mathrm{O}_{2}$ doesn't change at all, because your body can pick up your heart rate and your cardiac output. This is a normal subject. 
Kevin Ward: So what you've done is given an $\mathrm{O}_{2}$ flux test and basically showed the subject didn't need it.

Branson: Right. The oximeter says hypoxemia, but the tissue does not say hypoxemia. So you may be correct: we may need a better monitor.

Hess: I have a follow-up question about the venous blood gas. Are you talking about a peripheral venous or central venous?

Kevin Ward: Obviously, if you could get central venous hemoglobin oxygen saturation, that's fine and would give you a systemic picture, but recent data show that if you choose the right site- oral mucosa, the skin, etc- that these sites reflect whole-body tissue oxygenation, and some of them may act as early warning sites.

Hess: But you can't use a hand vein for a venous blood gas.
Kevin Ward: No, a hand vein may not be adequate. However, if it's noninvasive and it's a good reflection peripherally of what's going on centrally, that would be half of the equation. Then, if you had $\mathrm{S}_{\mathrm{pO}_{2}}$ and a monitor to report tissue venous hemoglobin oxygenation, you'd have continuous oxygen extraction ratio values, which might be more informative.

Hess: But you have to pick the right site.

Kevin Ward: And the right technology.

1. Schwartzstein RM, Lahive K, Pope A, Weinberger SE, Weiss JW. Cold facial stimulation reduces breathlessness induced in normal subjects. Am Rev Respir Dis 1987; 136(1):58-61

2. Galbraith BM, Fagan P, Phys GD, Perkins P, Lynch A, Booth S. Does the use of a handheld fan improve chronic dyspnea? A randomized controlled, crossover trial. J Pain Symptom Manage 2010;39(5):831-838.

3. Moore RP, Berlowitz DJ, Denehy L, Pretto JJ, Brazzale DJ, Sharpe K, et al. A ran- domised trial of domiciliary, ambulatory oxygen in patients with COPD and dyspnea but without resting hypoxaemia. Thorax 2011;66(1):32-37.

4. Kosowosky JM, Stephanides SL, Branson RD, Sayre MR. Prehospital use of continuous positive airway pressure for presumed pulmonary edema: a preliminary case series. Prehosp Emerg Care 2001;5(2):190196.

5. Abernethy AP, McDonald CF, Frith PA, Clark K, Herndon JE second, Marcello J, et al. Effect of palliative oxygen versus room air in relief of breathlessness in patients with refractory dyspnea: a double-blind, randomised controlled trial. Lancet 2010 4;376(9743):784-793.

6. Criner GJ, Celli, BR. Ventilatory muscle recruitment in exercise with $\mathrm{O}_{2}$ in obstructed patients with mild hypoxemia. J Appl Physiol 1987;63(1):195-200.

7. Emtner M, Porszasz J, Burns M, Somfay A, Casaburi R. Benefits of supplemental oxygen in exercise training in nonhypoxemic COPD patients. Am J Respir Crit Care Med 2003;168(9):1034-1042.

8. O'Donnell DE, D'Arsigny C, Webb KA. Effects of hyperoxia on ventilatory limitation during exercise in advanced COPD. Am J Respir Crit Care Med 2001;163(4): 892-898.

This article is approved for Continuing Respiratory Care Education credit. For information and to obtain your CRCE

(free to AARC members) visit

www.rcjournal.com 